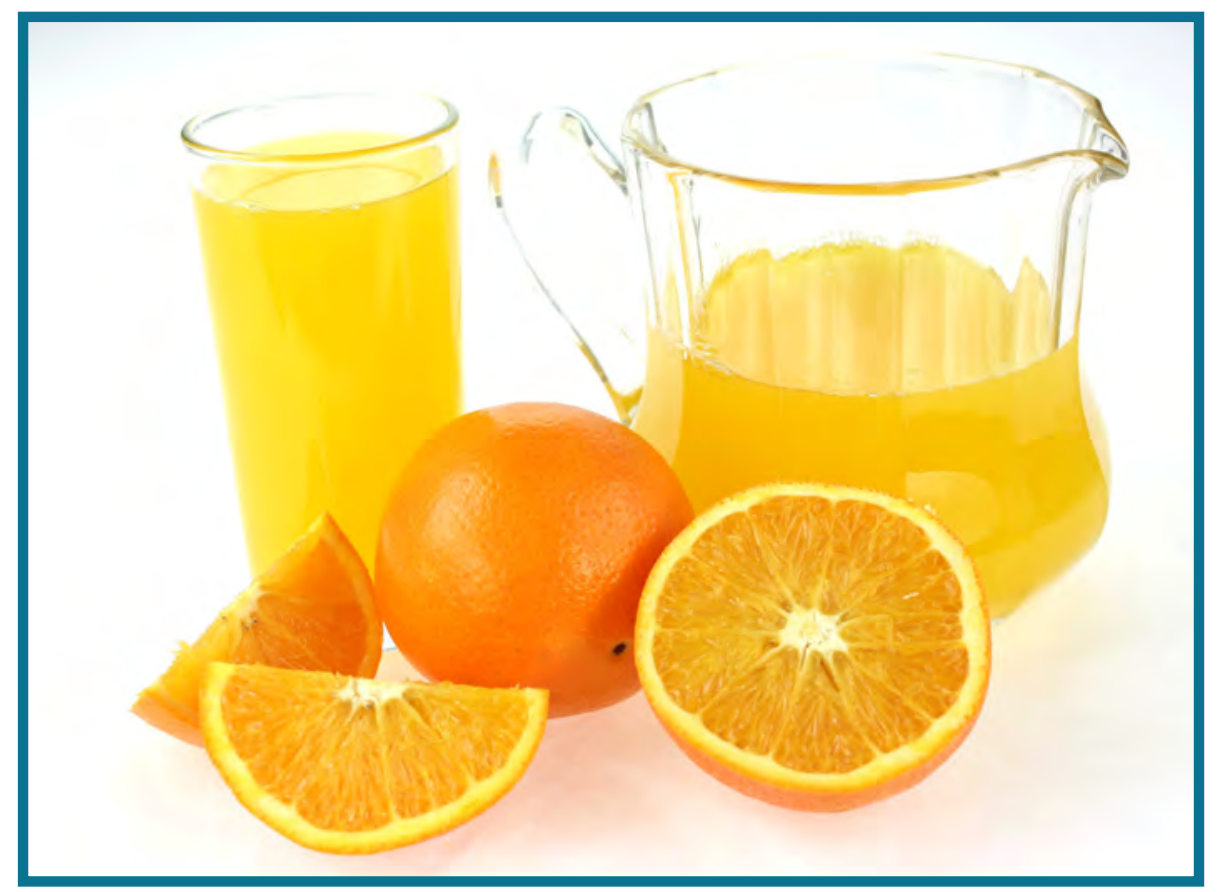

\title{
Exploring Consumer Response to Labeling a Processing Aid That Enhances Food Safety
}

\section{ABSTRACT}

Dimethyl dicarbonate (DMDC) can be used to reduce microbiological levels in juice. The United States does not require mandatory labeling of juice with DMDC. Food processors who value transparency need to communicate their processing methods without raising concerns about chemical use. This study used focus groups to identify consumer responses to and preferred communication approaches about the use of DMDC in juice. Orange juice consumers who were the household's primary food purchasers and were not employed in the food industry were recruited. Participants ( $N=58$ ) were asked their sources of food safety information, responses to label statements, and preferences for communicating about processing methods. Most participants obtained information on health and safety via the internet. The majority preferred the flavor of fresh-squeezed juice. Some mentioned they avoided processed foods. "No added chemicals," "no added sugar," and "all natural" were the most important labeling terms when they purchased juice, whereas "pasteurized" ranked the lowest. Though the participants' initial response to DMDC was negative, most were willing to try DMDC-treated juice after they received information. Some responded that labeling was unnecessary, but others believed strongly that consumers had the right to be informed. A label statement and web link were recommended to address the knowledge gap.

\section{INTRODUCTION}

Consumers value the flavor of fresh-squeezed juice. Whereas conventional thermal pasteurization enhances food safety, the process alters many sensory properties of fruit juice valued by consumers (23). However, because unpasteurized fruit juice can be contaminated with pathogenic bacteria, it poses a food safety risk to consumers. Over the past two decades, multiple foodborne Escherichia coli and Salmonella outbreaks have been linked to unpasteurized juice $(28,29)$. The U.S. Food and Drug Administration (FDA) allows unpasteurized juice to be produced and sold on-site at some grocery stores, health food stores, cider mills, farmers' markets, and juice bars (36). In the case of larger producers, the FDA hazard analysis critical 
control point regulations for juice stipulate a processing approach that achieves a minimum 5-log pathogen reduction (34).

Dimethyl dicarbonate (DMDC) performs a broad range of antimicrobial actions against pathogenic bacteria and is a common preservative in cold-sterilized soft drinks (9). When added to fruit juice, DMDC breaks down rapidly into methanol and carbon dioxide. The use of DMDC in beverages is approved by regulatory bodies, including the FDA, the European Food Safety Authority, and the Australian and New Zealand food safety agencies (2, 5, 35). In the United States, DMDC can be used as a yeast inhibitor, and its use must be declared on the label of carbonated, diluted beverages containing juice, fruit flavor, or both, with juice content not exceeding 50\% (32). After a review of studies of DMDC's effect on various yeast strains and on E. coli O157:H7 in several noncarbonated juice beverages, the FDA determined that DMDC is effective in microbial control for beverages' final packaging where the viable microorganism load has been reduced to 500 microorganisms per $\mathrm{mL}$ or less by current technologies (33). However, the regulations do not specify that labeling is required when DMDC is used as a microbial control agent in noncarbonated juice beverages containing up to and including 100\% juice (33). Previous studies mentioned that DMDC does not have to be declared on the label because it hydrolyzes into carbon dioxide and trace amounts of methanol (1).

Increasingly, consumers want to understand how their food is grown and processed (8). Nielsen's annual global sustainability survey reported that $46 \%$ of Americans agreed that food labeling impacts their purchase decisions (22). Such food labels and other information sources can provide information on how a product is sourced and treated. Onethird of American consumers consider brand transparency an important factor when purchasing food products (46). Transparent food supply procedures could potentially increase consumer willingness to buy and their perception of product quality (25). Clean label claims, especially organic claims, are key areas of activity in new food and beverage product development. From October 2017 to September 2018 , organic claims were made in over $21 \%$ of all U.S. soft drink launches (40).

Despite these trends, consumers can misinterpret certain food labels and food processing technologies. More than half of consumers reported in a survey the belief that products labeled "all natural" are healthier than those without this label, even when the two products bear the same nutrition facts panel (11). Syrengelas et al. reported that people are more willing to buy and pay more for products labeled "natural"; however, when informed that the word "natural" on meat products meant it was minimally processed, consumers' willingness to pay a premium for the product dropped to zero (30). Without knowing the benefits of a food processing technology, such as irradiation, and how it works, consumers may perceive more risks than benefits from the technology (6). Thus, before food companies adopt new processing technologies, they should develop a strategy to effectively communicate with consumers by understanding consumer perceptions of the process and their responses to labeling terms.

A focus group study utilizes a carefully planned discussion session in a permissive and nonthreatening environment to gather perceptions about a defined area of interest (14). This approach has been deployed to examine consumers' perceptions and food safety behaviors $(10,43)$. As a qualitative research approach, focus group interviews offer insight into these questions and allow researchers to study groups of people who possess characteristics critical to the research question. Through directed group discussion, participants provide qualitative data, and group communication allows insight into respondents' attitudes, feelings, beliefs, experiences, and reactions to the topic of interest. The researcher can also obtain direct quotations that capture a respondent's feelings. Focus groups should be continued until no new information is revealed. Krueger and Casey (14) indicate that three to six focus groups, with eight to 12 participants per group, are often sufficient to reveal a full range of responses to an issue.

A focus group study can shed light on a potential dilemma for fruit juice companies: though they may wish to utilize DMDC to enhance food safety, it is unclear what impact a declaration to consumers about the processing aid may have on their perceptions. If a company fails to disclose DMDC usage, and the public later learns about the practice, the company may be perceived as failing to be forthright about their process. Therefore, consumer research can help identify consumer priorities, their responses to information, and their preferred communication approaches. This study uses focus group research to explore consumer responses to the use of DMDC in commercially packaged fresh-squeezed orange juice, responses to different labeling terms, and preferences for methods of communicating the safety and benefits of DMDC usage.

\section{MATERIALS AND METHODS}

The authors conducted an internet search on the term "DMDC" and "dimethyl dicarbonate" in 2016 to review lay public literature about DMDC. The findings were then used to describe DMDC to focus group participants.

Men and women who were responsible for purchasing at least half of the household's groceries and who purchased fresh-squeezed orange juice were recruited through a national marketing research company (Opinions Inc., St. Louis, MO) and from an upper-division consumer research methods course at Sacramento State University. The study was conducted in 2017. Age and ethnic diversity were considered, but target numbers were not specified due to the small sample size. A research protocol specified by the 
institutional review board at the University of California, Davis, was followed.

Focus group participants were first asked about where they obtained information about healthy eating, whom they trusted, and how they responded to conflicting food safety information. Next, the discussion shifted to criteria related to the selection of orange juice. Their interest in label terms was explored by asking participants to rank the importance of "all natural," "no added chemicals," "organic," "no added sugar," "fresh-squeezed," and "pasteurized," on a numbered scale from 1 to 5 , with 1 meaning most important, and 5 meaning least important. Next, participants were asked about their preference for and experiences with fresh-squeezed juice. People were then asked whether they noticed whether the juice they purchased was pasteurized and what pasteurization meant to them. The safety benefit of pasteurization was affirmed, and the effect of pasteurization on flavor was acknowledged.

Next, an alternative treatment using the processing aid DMDC was described. Each participant was given a paper with the statements developed by the authors, and the statements were read aloud by the moderator or author. Participants were then asked for their reactions to DMDC usage, their interest in buying juice treated this way, and their comfort with the idea that mandatory juice labeling was not required. Participants discussed five statements proposed by the authors that a manufacturer might use in marketing material or on a label about juice treated with DMDC. Following the discussion, participants individually used a 3-point scale to rate their response to each statement: $1=$ like, 2 = okay, and 3 = don't like. The moderator clarified that "okay" meant acceptable, whereas "like" indicated preference. These statements were as follows:

- DMDC used for long-lasting quality

- DMDC used to preserve fresh-squeezed flavor

- DMDC used for quality and safety

- DMDC used to maintain quality

- Read about how we make our juice at www.company-website.com

Finally, participants were asked whether they would buy fresh-squeezed orange juice that had been treated with DMDC.

The focus groups were led by individual authors of this article, with one moderating and the other one taking notes. Sessions organized through the commercial firm were recorded and transcribed verbatim, whereas those conducted with college students were transcribed by the author not leading the discussion.

Quantitative data were analyzed using a post hoc Wilcoxon signed-rank test with a significance level of 0.0083 , which was the Bonferroni correction of significance level 0.05 among six comparison groups. The authors used the transcripts to analyze the qualitative data. First, major themes were identified after reading the transcripts. After applying first-level codes to key phrases, the codes were grouped with overlapping meaning and co-occurrence into themes and subthemes. When reporting the qualitative findings, the authors followed guidelines from Krueger and Casey's Focus Groups: A Practical Guide for Applied Research (14), which advised researchers to be cautious of "numbers being misleading in focus group reports... Not everyone answers every question... We encourage the use of modifiers like no one, a few, some, many, most, or all to describe how many people talked about an issue in a particular way" (14). Previous studies reporting focus group findings also employed modifiers instead of percentages or other numerals $(10,43)$.

\section{RESULTS}

\section{Information about DMDC}

Some popular lay internet sources, like WebMD, do not contain information on dimethyl dicarbonate but link to other sources, such as Wikipedia and the United Kingdom Food Guide $(37,39)$. Most lay internet information about DMDC defines the compound and addresses its use in beverages as a preservative (39). Some sources summarize the European Commission's evaluation of the compound's safety and describe its use $(5,41)$. One source incorrectly states that DMDC is not approved for use in New Zealand and Australia (2). Another web source describes DMDC as highly toxic and recommends that it should be banned (42).

The authors developed the following statements about DMDC based on the review of the lay and scientific literature:

- Dimethyl dicarbonate (abbreviated DMDC) is a preservative used in juice beverages, sports drinks, ice teas, and flavored waters in very minute quantities to ensure that the drink quality and safety are maintained.

- DMDC eliminates spoilage yeast and harmful bacteria.

- When added to a liquid, like juice, DMDC breaks down immediately by forming methanol, a form of alcohol, and carbon dioxide gas. The amount of methanol formed is comparable to what is formed naturally in juice.

- The use of DMDC is strictly regulated. The amount that would be added to juice to maintain quality and safety is considered safe by the European Food Safety Authority as well as the U.S. Food and Drug Administration.

- Because it is added when the juice is squeezed and breaks down within minutes, juice with DMDC is not required to be labeled.

\section{Consumer focus groups}

Three focus groups were held with persons recruited through the consumer research group and three from the university research methods class. A total of 58 persons participated in the focus groups: 33 recruited from Sacramento State University and 25 recruited through 
Opinions Inc. All participants met the selection criteria. The focus group size ranged from 8 to 14 participants. Most participants were women. Three men were among those recruited through Opinions Inc., and four men were among those recruited from Sacramento State. The college students were predominately in the 18 to 24 age range, whereas age was distributed widely among the Opinions Inc. consumers. Most of the Opinions Inc. group had completed at least some college. Their income ranged from less than $\$ 20,000$ a year to over $\$ 150,000$ (Table 1). Except where specified, participants from the professionally recruited focus group and the student participants expressed similar views about each topic discussed.

\section{Participant sources of information about healthy eating}

The internet was by far the most common source of information about healthy eating. Most participants googled a term and read the results. Several participants described WebMD as reliable, and MyFitnessPal app (21) was also mentioned as a useful source of information. Some college students reported that they would write a note to their physician, or contact their fitness coach or personal trainer, if they had a food or healthy eating question. Both students and professionally recruited participants sourced information from food labels, magazines, and clerks at health food stores. Few sought information from government agencies, such as the FDA or the U.S. Dept. of Agriculture (USDA). No one mentioned searching food companies' websites for information about food or health. Two participants from one of the professionally recruited focus groups regarded information from sources that promote the use of raw milk, Mother Earth News (20) and The Weston A. Price Foundation (38), as highly credible. Several participants said they favored minimally processed "organic" foods. Participants were skeptical of articles by marketing agencies. Most considered TV personalities to be paid advertisers and, therefore, did not trust statements from those personalities.

When asked how they would resolve conflicting information, participants said they would check additional information sources to see whether the negative information was reported widely. Several also mentioned they would listen to their bodies: if they had been eating something all their life with-

TABLE 1. Demographic characteristics of participants in a study of consumer preferences related to labeling of processing aids in orange juice

\begin{tabular}{c|c|c|c}
\multicolumn{2}{c|}{} & $\begin{array}{c}\text { Opinion Inc. consumers } \\
N=\mathbf{2 5}\end{array}$ & $\begin{array}{c}\text { College students } \\
\mathbf{N}=33\end{array}$ \\
\hline \multicolumn{2}{|c|}{} & 25 & 25 \\
\hline Age (yr) & 0 & 5 & 11 \\
\hline $18-24$ & 6 & 1 & 3 \\
\hline $25-34$ & 2 & 0 & 1 \\
\hline $35-39$ & 1 & 2 & 9 \\
\hline $40-44$ & 7 & 0 & 2 \\
\hline $45-49$ & 2 & 0 & 2 \\
\hline $50-54$ & 2 & 0 & 5 \\
\hline $55-59$ & 5 & & \\
\hline $60-64$ & & & \\
\hline
\end{tabular}

\section{Education}

\begin{tabular}{l|c|c|c}
\hline High school & 5 & 0 & 5 \\
\hline Some college & 13 & 33 & 46 \\
\hline College graduate & 7 & 0 & 7 \\
\hline
\end{tabular}

Income per year (US\$)

\begin{tabular}{l|c|c|c}
\hline$<20$ thousand & 1 & 15 & 16 \\
\hline $20-40$ thousand & 9 & 6 & 15 \\
\hline $40-60$ thousand & 7 & 5 & 12 \\
\hline $60-80$ thousand & 1 & 2 & 3 \\
\hline $80-100$ thousand & 3 & 1 & 4 \\
\hline Over 100 thousand & 4 & 4 & 8 \\
\hline
\end{tabular}


out ill effects, they would discount any negative information. Participants stated that good sensory characteristics of foods, previous experience with foods, and a low price might also lead them to ignore negative information.

\section{Factors influencing the selection of orange juice}

Participants expressed individual preferences for different types of orange juice: no pulp, with pulp, added calcium, low acid, low or no added sugar. Some specifically mentioned juice brands they believed to be fresh-squeezed; however, others were unsure whether the orange juice they purchased was fresh-squeezed. Participants knew the juice at a restaurant or supermarket was fresh-squeezed if they saw oranges and a juicer machine. Those participants who had their own orange tree squeezed them for juice. All liked the taste of fresh-squeezed juice, although some complained it was too acidic sometimes. Juice shelf life was irrelevant to most people because the juice was consumed quickly.

Participants ranked the importance of six label statements individually in making their decision to purchase orange juice: "no chemical added" was ranked significantly more important than "fresh-squeezed," and "fresh-squeezed" was ranked significantly more important than "pasteurized." There was no significant difference between the student participant group and the professionally recruited consumer participant group with a Kruskal-Wallis independent sample test, $P<0.05$ (Table 2).

Some participants grappled with the term "fresh." Some suggested that "fresh-squeezed" meant the juice was squeezed within a day of being purchased, or within the last $24 \mathrm{~h}$. Participants then wondered aloud and discussed how the juice could be in a sealed container if it had just been squeezed. Most participants believed that "fresh" referred to the distinctive taste of the juice rather than to the precise number of hours since the juice had been squeezed.

\section{Understanding of pasteurization}

All but one participant believed that all juice they purchased at the supermarket was likely to be pasteurized. Most, but not all, knew the function of pasteurization. A few indicated that their knowledge of pasteurization was limited. Some mistakenly believed that pasteurized meant that the product was sterile, that is, that all bacteria had been destroyed. All acknowledged that pasteurized juice tasted different than fresh-squeezed juice. The participant who used the Weston Price website drank raw milk and was skeptical about the benefits of pasteurization.

\section{Reactions to DMDC}

People reacted negatively to the words "dimethyl dicarbonate." They had not heard the term before and viewed it as a chemical. They wanted to know what it did, how it was derived, the longterm effects of consumption, and how long the chemical had been studied.

After hearing the description of DMDC, many did not understand how a chemical could break into two components and no longer be present in the juice when a consumer purchased it. Participants thought that if DMDC had been added, it must still be present in the juice. Some queried how much methanol was present in the juice and whether the amount was harmful. People wondered whether DMDC was used in other countries. Several were reassured by its approval in Europe. The fact that DMDC was already in tea, sports drinks, flavored water, and other products was reassuring. One woman said, "So we are already drinking it, and we are okay."

People believed food companies wanted to use DMDC to avoid the cost of pasteurization. When they were reminded that the taste of fresh-squeezed juice and customer safety were the driving forces behind this approach, several

TABLE 2. Participants' mean ranking scores of the importance of each label term, in a study of consumer preferences related to labeling of processing aids in orange juice ${ }^{a}$

\begin{tabular}{|c|c|c|c|}
\hline & $\begin{array}{l}\text { All participants } \\
\qquad N=\mathbf{5 8}\end{array}$ & $\begin{array}{l}\text { Student participants } \\
\qquad N=33\end{array}$ & $\begin{array}{l}\text { Opinion Inc. participants } \\
\qquad N=25\end{array}$ \\
\hline No chemical added & $2.67 \mathrm{~A}$ & $2.76 \mathrm{~A}$ & $2.56 \mathrm{~A}$ \\
\hline No sugar added & $2.95 \mathrm{AB}$ & $2.97 \mathrm{~A}$ & $2.92 \mathrm{AB}$ \\
\hline All natural & $3.00 \mathrm{ABC}$ & $3.12 \mathrm{~A}$ & $2.84 \mathrm{AB}$ \\
\hline Freshly squeezed & $3.78 \mathrm{BC}$ & $3.67 \mathrm{AB}$ & $3.92 \mathrm{AB}$ \\
\hline Organic & $3.90 \mathrm{CD}$ & $3.64 \mathrm{AB}$ & $4.24 \mathrm{BC}$ \\
\hline Pasteurized & $4.74 \mathrm{D}$ & $4.88 \mathrm{~B}$ & $4.56 \mathrm{C}$ \\
\hline Friedman test $P$-value & $P<0.001$ & $P<0.001$ & $P<0.001$ \\
\hline
\end{tabular}

${ }^{a}$ Score of 1 is most important; 5 is least important. Within each column, means with the same letter are not significantly different. 
suggested that the juice should be labeled "tastes more like fresh." Another said that "as good as pasteurized" should be added to the label.

\section{Responses to labeling}

Participants were divided regarding labeling practices. A minority believed that DMDC labeling was unnecessary because the chemical was no longer present and the FDA had ruled it safe. Moreover, the term could frighten consumers away from purchasing a healthy product. Statements capturing this attitude include the following:

I'm sure there are a lot of products that we're eating and drinking, and we have no idea what's in them. [Some products] are not labeled, and we still eat and drink them. So, it doesn't bother me.

I recommend not to say anything. I think it just makes the public crazy, and it's just one more thing for them to have to research.

If it's FDA approved, then boom, it's done. I don't see a problem with that as a consumer.

The majority of participants believed strongly, however, that the consumer should be informed about how their food was processed. As a result of our discussion, they recognized that the words "contains DMDC" would be misleading because the chemical was no longer present; some suggested including "processed with DMDC to maintain quality and safety." Participants noted that those concerned about food safety could then google DMDC to find out more about the chemical. Representative comments include the following:

It's my right to know what it's been processed with. You don't have to care, and you don't have to know, and that's your right if you want to pass that up, but I don't want to pass that up, and I do want to know.
I don't think they should have a long explanation, just like they don't have a long explanation for "pasteurized." If you want to know what that is, you're going to have to look it up. But I think they should identify that that's in there - or that has been used.

I think they should put it on because, you know, she (another participant) wants to know.

The water bottle says: "purified water enhanced with minerals for a pure, fresh taste." There's a way they could label it just like that.

One participant indicated that her child had a condition she believed to be caused by what he ate. Because she monitored her child's food consumption closely, she would need to know how the juice was processed:

I just found out that my son has ADHD, and he got it because [of] a lot of the things that he eats. And, if this is something that's going to help-I mean, hurt or help the situation-I would rather know what it is than to give it to him. So, I would want to know.

Participants said the failure to acknowledge DMDC use would make the company appear to be hiding something from the public. In their view, the failure to communicate suggests a problem with the product:

If you have nothing to hide, put it out there. Tell me that that was your process. So like you said, one, it lets us know that it has a better nutrient level. Two, it tells you that it has a better taste level. Three, it's protecting the label, the company, by doing the process.

One participant specifically sought out the juice that was pasteurized. She said that, although she would not consider fresh-squeezed juice a safe food choice, if she knew an alternative to pasteurization had been employed, she would consider selecting the juice. Identifying DMDC usage would then increase her likelihood of purchasing the juice:

TABLE 3. Participants' mean rating score of label statements about using DMDC in freshly squeezed orange juice, in a study of consumer preferences related to labeling of processing aids in orange juice ${ }^{a}$

\begin{tabular}{l|c} 
& All participants $N=25$ \\
\hline Web link & $1.32 \mathrm{~A}$ \\
\hline Quality and safety & $1.44 \mathrm{~A}$ \\
\hline Preserve fresh squeezed flavor & $1.84 \mathrm{AB}$ \\
\hline Maintain quality & $1.96 \mathrm{~B}$ \\
\hline Long-lasting quality & $2.24 \mathrm{~B}$ \\
\hline Friedman test $P$-value & $P<0.001$ \\
\hline
\end{tabular}

a3-point scale: 1 = like, 2 = OK, 3 = don't like. Within each column, means with the same letter are not significantly different. 
I do want to know [if DMDC is used]. If it's not pasteurized and DMDC is not used, I'm not going to buy it. It's not safe enough.

\section{Potential methods and content of communications about DMDC}

When asked how the food industry could communicate with consumers, participants mentioned commercials, Facebook, and food samplers, such as those who offer food samples at the supermarket. Advertisements and articles in food- and health-related magazines containing a brief description were also suggested. The extensive discussion focused on the content of the message and the value of a web link. Label statements containing information about a "web link" and "quality and safety" were preferred significantly more than "maintain quality" and "long-lasting quality" (Table 3). Several participants suggested that the statements could be combined to increase the effectiveness of messaging.

Whereas participants favored a web link for those who wanted more information, they suggested that the benefits of using DMDC and the safety evaluation of DMDC should be included. Some noted the likelihood of articles critical of DMDC, so they suggested that the company prepare the customer with science-based and validated information about its safety. Participants responded that they trusted the company more when it provided information without prompting. The following quotes capture this sentiment:

Use a website because people who are going to want to read it are going to read it. They're going to read all the research. But you have to be wary because they're going to find an article that says it's bad, just as some say it's good. So beat them to the punch by saying all the good stuff.

If you're going to put it on there, let people know ahead of time. Tell the positives of why they're doing it, it's going to be great for you, and orange juice is going to last longer, your kids can enjoy it longer. And then at the same time maybe put it on the label. But if they're not going to do a positive ad campaign, just don't label it because it's just going to make people panic.

\section{DISCUSSION}

Participant attitudes toward label terms in this study are comparable to those documented among consumers in general. "No chemical added" was ranked as the most important factor impacting a consumer's purchasing decision. The International Food Information Council's 2019 consumer food survey reported that four of the top five food safety issues among U.S. consumers were concerns about cancer-causing chemicals in food, chemicals (in general) in food, pesticides, and food additives (11). The International Food Information Council's survey also reported that label claims, such as "natural," were the most impactful on purchasing decisions. Consumers perceived "natural” to mean "no preservatives," whereas they perceived "chemicalsounding preservatives" as "unnatural" (16). In this study, consumers perceived DMDC as an unfamiliar chemical used as a preservative, and they had a negative reaction to the words "dimethyl dicarbonate (DMDC)."

Similarly, participants in this study viewed "all natural" and "organic" positively. As mentioned in the introduction, when consumers were told that the USDA's definition of the term "natural" is that the product is minimally processed, few were willing to pay a premium (30). Some consumers believed that food bearing "organic" labels was healthier, tasted better, and had environmental benefits $(3,15,19,26)$. Many studies reported little association between organic farming and those perceived benefits. Organic foods were not necessarily more nutritious (18), more sustainable (13), or better tasting (44). For example, a recent review article reported that there were limited differences in the composition of organic and conventional crops (18). A previous sensory study reported that consumer preference and consumer perceived sensory qualities were not significantly different between organically and conventionally grown vegetables (44). Knudsen and colleagues' (13) life cycle analysis revealed that organic farming had a higher carbon footprint, which suggested that consumers' perception of environmental benefits may not be supported. Nevertheless, the buying "organic" trend has led some consumers to believe that this method of production is the best for human and environmental health (12).

Participants considered "pasteurized" less important than the other statements provided, "no chemical added" and "fresh-squeezed." This could be because pasteurization was taken for granted by participants. Alternatively, this ranking could reflect the attitudes of those who consider raw milk more healthy than pasteurized milk $(4,17)$. Two of the focus group participants held this view. On the other hand, some participants were aware of safety issues and would not purchase a juice without a pathogen kill-step. Our study's findings suggested a continued need to alert the public to the importance of measures to enhance food safety.

The finding that consumers sought health information from various sources, like WebMD, My Fitness Pal, or food labels, was consistent with previous studies that reported the internet as a major source of health information $(24,45)$. Nearly $40 \%$ of young consumers (ages 18 to 30) obtained health information from an internet search engine, and a quarter relied on popular internet health websites, such as WebMD (24). This study indicated that more science-based food safety and health information should be developed for the internet. However, information about DMDC was not available through these sources.

When asked about their preferences regarding the delivery of information about DMDC, many reported that they wanted to find information on the juice company's website. This suggests that food companies who plan to utilize DMDC or other ingredients or technologies unfamiliar to consumers should be prepared to meet consumer expectations and provide information about the processes. 
The finding that some participants trust information from websites that promote raw milk was consistent with previous research findings that health information on the internet can be biased and lacking in scientific evidence (7). Future studies could focus on evaluating social media influencers' impact on consumer perceptions of DMDC, other ingredients, processing aids, or new food technologies.

Participants' belief that food companies would use DMDC to avoid the cost of pasteurization further emphasizes the need for companies to increase communication with consumers. The study's participants did not realize that DMDC could enhance food safety without losing the taste of fresh-squeezed juice. Some participants wondered how freshsqueezed juice could be marketed in a sealed container. They were unaware that bacteria reduction meant the juice had a longer shelf life, even though they were less concerned about shelf life in general. They valued the unique flavor of freshly squeezed juice instead.

This study also found that participants wanted to learn about the benefits and safety of DMDC use. Some were reassured about DMDC use after learning that the chemical was approved in Europe. The importance of communicating benefits is consistent with a previous study that evaluated the effect of information on consumers' intent to purchase irradiated foods (6). Information on the benefits of food irradiation was found to be more effective in increasing purchase intent than information about authorities' approval of the process.

Some participants believed strongly in their right to know how their food had been processed. This is consistent with the widely reported quest for transparency and openness in the food industry. Most consumers (67\%) want to know what goes into the food they buy (22). This phenomenon was also observed in other food transparency issues, like the application of genome editing in foods. Consumers want to engage in the application and regulation of genome editing of foods, even if they may hold different views about this technology (27). The craving for transparency may be related to decreased trust in food production and distribution. Some researchers proposed that consumers' decreased proximity to farming and lack of knowledge about the processes contribute to this skepticism $(8,31)$.

\section{Limitations}

Although the study was carefully designed, there are limitations to focus group research, including small sample size and nonrandomized sample selection. Results from this study cannot be generalized to the entire consumer population; however, the findings do identify themes that can be quantified through further research.

\section{CONCLUSIONS}

Fruit juice companies have striven to maintain the unique flavor of fresh-squeezed juice while meeting the 5-log reduction requirement of the FDA. If company policy calls for openness and transparency and product quality is enhanced by using a processing aid with an unfamiliar chemical name, should the company disclose its use to their customers?

This question points to a dilemma for fruit juice companies: unfamiliar processing aids, such as DMDC, that can maintain flavor can also cause consumer anxiety. A company is well advised to initiate communication about the processing aid's consumer benefits and its safety evaluation. Combining the two label phrases preferred by this study's focus group participants would likely result in increased consumer acceptance. These phrases are "specially treated for quality and safety" and "read about how we make our juice at www.company-website.com."

The company's webpage could include information about how oranges are sourced, what procedures are followed to maintain quality and safety, and information on DMDC, such as that used in this focus group. Because those who like to search the web may well seek out other sites for confirmation, it would be helpful to include links on the webpage to sources that contain scientific information about DMDC. Wikilinks are used commonly by the general public. Although it is subject to rewriting, a wikilink is readable and correct at the time of this writing. The code of federal regulation may be referenced. It is not lay reader-friendly, but it is authoritative.

Our findings indicate that, although labeling is not required, some people are adamant about their right to be informed about how their food is processed. A label that indicated the juice was treated for quality and safety, combined with a web link, was received well by all participants. This approach could direct those who seek information on how the product was handled to a site explaining the benefits of the process, and it could be ignored by those who were uninterested. This study models an approach a food processor could use to communicate with consumers in a transparent manner.

\section{ACKNOWLEDGMENTS}

We thank the study's participants. This material is partially supported by the National Institute of Food and Agriculture, U.S. Dept. of Agriculture, Hatch project 1016049.

\section{REFERENCES}

1. Assatarakul, K. 2017. Degradation kinetic models and inactivation of pathogenic microorganisms by dimethyl dicarbonate in fresh mandarin juice. J. Food Saf. 37:e12319.
2. Australian Government Federal Register of Legislation. Not dated. Australia New Zealand food standards code-schedule 18processing aids. Available at: https://www. legislation.gov.au/Details/F2018C00624. Accessed 19 May 2020.
3. Bi, X., Z. Gao, L. A. House, and D. S. Hausmann. 2015. Tradeoffs between sensory attributes and organic labels: the case of orange juice. Int. J. Commun. Stud. 39:162-171. 
4. Bovbjerg, M. L., J. G. Waite-Cusic, C. C. Häse, and K. P. Poulsen. 2018. Knowledge, attitudes and practices regarding raw milk consumption in the Pacific Northwest. Food Prot. Trends 38:104-110.

5. European Food Safety Authority. 2015. Scientific opinion on the re-evaluation of dimethyl dicarbonate as a food additive. Available at: https://www.efsa.europa.eu/en/efsajournal/ pub/4319. Accessed 4 December 2019.

6. Feng, Y., C. Bruhn, and D. Marx. 2016. Evaluation of the effectiveness of food irradiation messages. Food Prot. Trends $36: 272-283$.

7. Garrett, B., E. Mallia, and J. Anthony. 2019 Public perceptions of internet-based health scams, and factors that promote engagement with them. Health Soc. Care Community 27:672-686.

8. Giampietri, E., F. Verneau, T. Del Giudice, V. Carfora, and A. Finco. 2018. A theory of planned behaviour perspective for investigating the role of trust in consumer purchasing decision related to short food supply chains. Food Qual. Prefer. 64:160-166.

9. Golden, D., R. Worobo, and C. Ough. 2005. Dimethyl dicarbonate and diethyl dicarbonate, p. 305-326. In P. M. Davidson, J. N. Sofos, and A. L. Branen (ed.), Antimicrobials in food. CRC Press, Boca Raton, FL.

10. Henley, S. C., S. E. Stein, and J. J. Quinlan. 2012. Identification of unique food handling practices that could represent food safety risks for minority consumers. J. Food Prot. 75:2050-2054.

11. International Food Information Council Foundation. 2019. 2019 Food and health survey. Available at: https://foodinsight. org/2019-food-and-health-survey/. Accessed 14 May 2020.

12. Kim, S.-W., J. Lusk, and B. Brorsen. 2018. "Look at me, I'm buying organic": the effects of social pressure on organic food purchases. J. Agric. Resour. Econ. 43:364-387.

13. Knudsen, M. T., A. Meyer-Aurich, J. E. Olesen, N. Chirinda, and J. E. Hermansen. 2014. Carbon footprints of crops from organic and conventional arable crop rotations - using a life cycle assessment approach. J. Clean. Prod. 64:609-618.

14. Krueger, R. A., and M. A. Casey. 2014. Focus groups: a practical guide for applied research, 5th ed. Sage Publications, Thousand Oaks, CA.

15. Lee, W.-C., M. Shimizu, K. M. Kniffin, and B. Wansink. 2013. You taste what you see: do organic labels bias taste perceptions? Food Qual. Prefer. 29:33-39.

16. Lusk, J. 2019. Consumer perceptions of "natural" foods. Food Technol. 73:42-46.

17. Markham, L., G. Auld, M. Bunning, and D. Thilmany. 2014. Attitudes and beliefs of raw milk consumers in Northern Colorado. J. Hunger Environ. Nutr. 9:546-564.

18. Mie, A., H. R. Andersen, S. Gunnarsson, J. Kahl, E. Kesse-Guyot, E. Rembiałkowska, G. Quaglio, and P. Grandjean. 2017. Human health implications of organic food and organic agriculture: a comprehensive review. Environ. Health 16:111.

19. Monier-Dilhan, S., and F. Bergès. 2016. Consumers' motivations driving organic demand: between self-interest and sustainability. Agric. Resour. Econ. Rev. 45:522-538.

20. Mother Earth News. 2019. Available at: https://www. motherearthnews.com/. Accessed 5 December 2019.

21. MyFitnessPal. 2019. Available at: https:// www.myfitnesspal.com/. Accessed S December 2019.

22. Nielsen FMCG and Retail. 2018. It's clear: transparency is driving FMCG growth. Available at: https://www.nielsen.com/ us/en/insights/news/2018/its-cleartransparency-is-driving-fmcg-growth.html. Accessed 11 January 2018.

23. Parish, M. E. 1998. Orange juice quality after treatment by thermal pasteurization or isostatic high pressure. $L W T$ - Food. Sci. Technol. 31:439-442.

24. Prybutok, G., and S. Ryan. 2015. Social media: the key to health information access for 18- to 30-year-old college students. Comput. Inform. Nurs. 33:132-141.

25. Sander, F., J. Semeijn, and D. Mahr. 2018. The acceptance of blockchain technology in meat traceability and transparency. Brit. Food J. 120:2066-2079.

26. Sax, J., and N. Doran. 2016. Food labeling and consumer associations with health, safety, and environment. J. Law Med. Ethics 44:630-638.

27. Scheufele, D., M. Xenos, E. Howell, K. Rose, D. Brossard, and B. Hardy. 2017. U.S. attitudes on human genome editing. Science 357:553-554.

28. State of Michigan. 2005. Michigan investigates outbreaks of Salmonella, disease linked to unpasteurized orange juice. Available at: https://www.michigan.gov/ som/0,4669,7-192-29942_34762-122461-,00.html. Accessed 4 December 2019.

29. Stearns, D. 2015. A decade history of E. coli outbreaks linked to unpasteurized apple juice. Available at: https://www.foodpoisonjournal. com/foodborne-illness-outbreaks/a-historyof-e-coli-outbreaks-linked-to-unpasteurizedapple-juice/. Accessed 4 December 2019.

30. Syrengelas, K., K. DeLong, C. Grebitus, and R. Nayga, Jr. 2017. Is the natural label misleading? Examining consumer preferences for natural beef. Appl. Econ. Perspect. Policy $40: 445-460$.

31. Thorsøe, M., and C. Kjeldsen. 2016. The constitution of trust: function, configuration and generation of trust in alternative food networks. Sociol. Rural. 56:157-175.

32. U.S. Food and Drug Administration. 1996. Food additives permitted for direct addition to food for human consumption; dimethyl dicarbonate. Fed. Regist. 61:26786-26788.
33. U.S. Food and Drug Administration. 2001. Food additives permitted for direct addition to food for human consumption; dimethyl dicarbonate. Fed. Regist. 66:13652-13653.

34. U.S. Food and Drug Administration. 2004 Guidance for industry: juice hazard analysis critical control point hazards and controls guidance, 1st ed. Available at: https://www. fda.gov/regulatory-information/search-fdaguidance-documents/guidance-industryjuice-hazard-analysis-critical-controlpoint-hazards-and-controls-guidance-first. Accessed 4 December 2019.

35. U.S. Food and Drug Adminstration. 2015. 21 CFR 172.133. Title 21-Food and drugs, part 172-Food additives permitted for direct addition to food for human consumption, sec. 172.133-Dimethyl dicarbonate. Available at: http://www. accessdata. fda.gov/scripts/cdrh/cfdocs/ cfcfr/CFRSearch.cfm?fr=172.133. Accessed 4 December 2019

36. U.S. Food and Drug Administration. 2017. What you need to know about juice safety. Available at: https://www.fda.gov/food/buy store-serve-safe-food/what-you-need-knowabout-juice-safety. Accessed 2 August 2020.

37. UK Food Guide 2003-2019. 2019. E242 dimethyl dicarbonate. Available at: http:// www.ukfoodguide.net/e242.htm. Accessed 5 December 2019.

38. Weston A. Price Foundation. 2019. Available at: https://www.westonaprice.org/. Accessed 5 December 2019

39. Wikipedia. Not dated. Dimethyl dicarbonate. Available at: https://en.wikipedia.org/ wiki/Dimethyl_dicarbonate. Accessed 5 December 2019.

40. Williams, L. 2019. Mindful consumers drive clean label momentum. Food Technol. 73:34-43.

41. Wine Folly. 2016. Wine additives: the good, the bad \& the ugly wine folly. Available at: http://winefolly.com/review/wine-additives. Accessed 19 September 2016.

42. Wotzinur.food. Not dated. Preservatives E 242 dimethyl dicarbonate. Available at: http://www.wotzinurfood.com/e242dimethyl-dicarbonate.html. Accessed 19 September 2016.

43. Yang, L. L., M. L. Khalid, M. D. Duong, J. N. B. Kessinger, B. N. Ong, T. A. Drape, R. C. Williams, T. Archibald, B. J. Chapman, and R. R. Boyer. 2019. Consumer response to mechanically tenderized beef (MTB) and MTB labels: an exploratory focus group study. J. Food Prot. 82:1484-1495.

44. Zhao, X., E. Chambers IV, Z. Matta, T. M. Loughin, and E. E. Carey. 2007. Consumer sensory analysis of organically and conventionally grown vegetables. J. Food Sci. 72:S87-S91.

45. Zhao, Y., and J. Zhang. 2017. Consumer health information seeking in social media: a literature review. Health Info. Libr. J. 34:268-283.

46. Zoya, G. 2018. Most people think food labels are misleading. Available at: https://nypost. com/2018/06/07/most-people-think-food-labels-are-misleading/. Accessed 11 January 2019. 